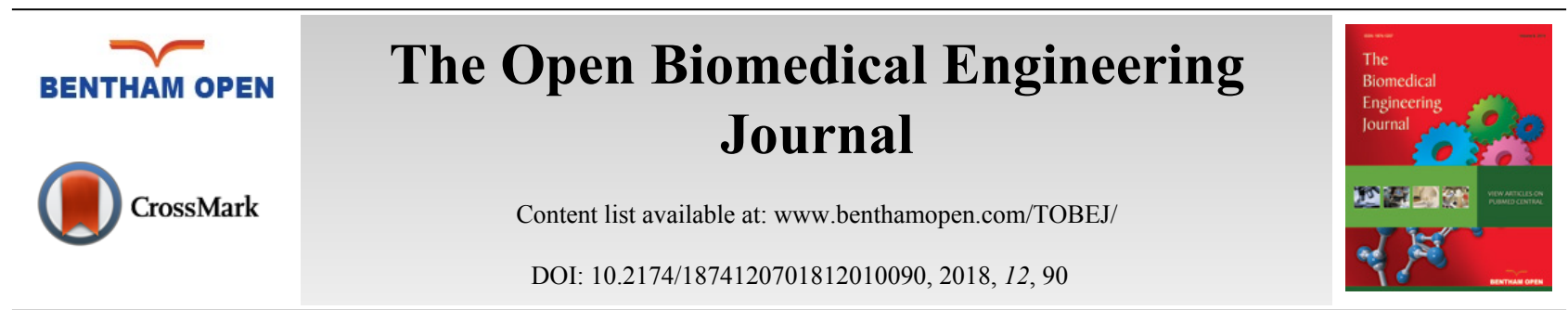

\title{
CORRIGENDUM
}

\section{F.E.M. Stress-Investigation of Scolios Apex}

A. Daghighi ${ }^{1, *}$, H. Tropp ${ }^{2, \#}$, N. Dahlström ${ }^{3}$ and A. Klarbring ${ }^{4}$

${ }^{I}$ Department of Clinical and Experimental Medicine, Linköping University, 58183 Linköping, Sweden

${ }^{2}$ Department of Clinical and Experimental Medicine \& Division of Surgery Orthopedics and Oncology, Linköping University, 58183 Linköping, Sweden

${ }^{3}$ Center for Medical Image Science and Visualization, Linköping University, 58183 Linköping, Sweden

${ }^{4}$ Department of Management and Engineering, Division of Solid Mechanics, Linköping University, 58183 Linköping, Sweden

\section{F.E.M. Stress-Investigation of Scolios Apex}

The Open Biomedical Engineering Journal, 2018, 12: 51-71

The author has removed the provided Telephone Number. 